\title{
Low SARS-CoV-2 seroprevalence but high perception of risk among healthcare workers at children's hospital before second pandemic wave in Germany
}

\author{
Marietta Neumann ${ }^{1}$ (D) Annette Aigner ${ }^{2} \cdot$ Eileen Rossow $^{3} \cdot$ David Schwarz $^{4,7} \cdot$ Maria Marschallek $^{1}$. \\ Jörg Steinmann ${ }^{5,8} \cdot$ Ralf Stücker $^{6} \cdot$ Ingo Koenigs $^{4,7} \cdot$ Philippe Stock $^{1}$
}

Received: 27 January 2021 / Accepted: 15 July 2021 / Published online: 20 August 2021

(c) The Author(s) 2021

\begin{abstract}
Background Healthcare workers are considered a particularly high-risk group during the coronavirus disease 2019 (COVID19) pandemic. Healthcare workers in paediatrics are a unique subgroup: they come into frequent contact with children, who often experience few or no symptoms when infected with severe acute respiratory syndrome coronavirus 2 (SARS-CoV-2) and, therefore, may transmit the disease to unprotected staff. In Germany, no studies exist evaluating the risk of COVID-19 to healthcare workers in paediatric institutions.

Methods We tested the staff at a large children's hospital in Germany for immunoglobulin (Ig) G antibodies against the nucleocapsid protein of SARS-CoV-2 in a period between the first and second epidemic wave in Germany. We used a questionnaire to assess each individual's exposure risk and his/her own perception of having already been infected with SARS-CoV-2.

Results We recruited 619 participants from all sectors, clinical and non-clinical, constituting $70 \%$ of the entire staff. The seroprevalence of SARS-CoV-2 antibodies was $0.325 \%$ (95\% confidence interval $0.039-1.168$ ). Self-perceived risk of a previous SARS-CoV-2 infection decreased with age (odds ratio, 0.81; 95\% confidence interval, 0.70-0.93). Having experienced symptoms more than doubled the odds of a high self-perceived risk (odds ratio, 2.18; 95\% confidence interval, 1.59-3.00). There was no significant difference in self-perceived risk between men and women.

Conclusions Seroprevalence was low among healthcare workers at a large children's hospital in Germany before the second epidemic wave, and it was far from a level that confers herd immunity. Self-perceived risk of infection is often overestimated.
\end{abstract}

Keywords Health personnel $\cdot$ SARS-CoV-2 $\cdot$ Seroepidemiologic studies $\cdot$ Pediatrics

\section{Introduction}

The COVID-19 pandemic has caused a burden to individuals, the healthcare system, and economies worldwide. The role of children in the spread of the pandemic

Marietta Neumann

mariettaneumann@gmail.com

1 Department of Paediatrics, Altona Children's Hospital, Universität Hamburg, Altonaer Kinderkrankenhaus, Bleickenallee 38, 22763 Hamburg, Germany

2 Corporate Member of Freie Universität Berlin and Humboldt-Universität $\mathrm{Zu}$ Berlin, Institute of Biometry and Clinical Epidemiology Berlin, CharitéUniversitätsmedizin Berlin, Berlin, Germany

3 Department of Neonatology and Paediatric Intensive Care Medicine, Altona Children's Hospital, Hamburg, Germany remains unclear and is subject to ongoing research and frequent discussion at the political level. Transmission patterns in schools, childcare centres and households have been the basis of most epidemiologic studies involving children and COVID-19 [1-4], but to our knowledge, no

4 Department of Paediatric Surgery, Altona Children's Hospital, Hamburg, Germany

5 Labor Dr. Fenner and Colleagues, Hamburg, Germany

6 Department of Paediatric Orthopaedics, Altona Children's Hospital, Hamburg, Germany

7 Department of Paediatric Surgery, University Medical Centre Hamburg-Eppendorf (UKE), Hamburg, Germany

8 Department of Paediatrics, Altona Children's Hospital, Hamburg, Germany 
studies exist assessing whether adults in close contact with children in their work environment are more likely to acquire the disease. However, evidence concerning the course of COVID-19 in children has been consistent: it is often mild or without any symptoms at all [5-8]. Seroprevalence may be up to sixfold higher than reported cases in children, implying large numbers of undiagnosed infected children [9].

Healthcare workers (HCWs) are considered a particularly high-risk group in the course of any infectious epidemic. In the 2009 influenza pandemic, HCWs were disproportionately affected [10], and the same appears to be true for COVID-19 [11]. However, research has also yielded heterogeneous results, suggesting a variety of risk and protective factors. A single study in Spain found a low seroprevalence among paediatric HCWs [12], but other than that, little is known about this subgroup despite the uncertainty of SARS-CoV-2 transmissibility by children.

To help close this gap, we tested staff members at a large children's hospital in Germany for SARS-CoV-2 immunoglobulin (Ig) $\mathrm{G}$ antibodies, to quantify the previous exposure to SARS-CoV-2 among this particular subpopulation. We hypothesized that HCWs at a children's hospital might be at a particularly high risk of SARSCoV-2 exposure because children with asymptomatic COVID-19 present for unrelated reasons, and, therefore, HCW s come into unsuspected close contact without adequate personal protective equipment (PPE). To our knowledge, this is the first seroprevalence study for paediatric HCWs in Germany.

In addition to the potentially measurable risk for an infection, the self-perceived risk of an individual due to his/her everyday exposures is of great scientific interest. It may be an expression of how serious the threat by this ongoing pandemic is considered, and of the confidence placed in strategies applied to limit it. It may also influence preventive behaviours, such as social distancing and handwashing [13]. A nationwide survey in Germany found that $60 \%$ of $\mathrm{HCW}$ s had concerns regarding their own health [14], and Behrens et al. found that while actual seroprevalence was low, the perceived risk among HCWs at a German hospital was considerable and decreased with time. They also found that women had a higher self-perceived risk than men [15]. Understanding risk perceptions in the general public and among subgroups may ultimately guide effective communication about the pandemic to the public.

\section{Methods}

\section{Ethical considerations}

This study was approved by the Ethical Review Committee of the Medical Association (Aerztekammer) Hamburg in Germany (PV7404). Written informed consent was obtained from all participants prior to participation in the study.

\section{Recruitment}

We aimed at recruiting all personnel working at the Altona Children's Hospital in Hamburg, Germany, which constitutes a deliberately chosen cluster of the entire population of paediatric hospital staff; therefore, we used non-probability cluster sampling with subsequent total population sampling. Staff members were recruited with announcements on internal mailing lists and were additionally addressed personally. Staff members across all sectors were invited to participate, including trainees and non-clinical staff. Non-clinical HCWs, while presumably at a lower exposure risk, were included to diversify our sample. We excluded individuals with congenital or acquired immunodeficiencies, those who had been absent from work since before COVID-19 emerged in Germany, and minors under the age of 18 years. Data were acquired over a 1-month period, 6 months after the first COVID-19 case in Hamburg was diagnosed, i.e. after the first epidemic wave (Fig. 1).

\section{Test methods}

Serum blood samples were obtained from each subject and were tested for SARS-CoV-2 anti-nucleocapsid IgG antibodies by enzyme-linked immunosorbent assay (ELISA) using a CE-marked kit 'Anti-SARS-CoV-2 NCP Elisa (IgG)' by EUROIMMUN, Lübeck, Germany. This is a semi-quantitative assay based on the ratio of the extinction of the sample and that of a calibrator. A ratio of $<0.8$ is considered a negative result, $\geq 1.1$ positive, and $\geq 0.8$ and $<1.1$ borderline. EUROIMMUN reports a test sensitivity of $94.6 \%$ when samples are obtained more than 10 days after symptom onset, and a specificity of $99.8 \%$. The rationale for using this assay was the superior immunogenicity of the nucleocapsid structural protein $(\mathrm{N})$ compared to the spike (S) antigens in SARS-CoV [16]. Anti-N antibody tests in SARS-CoV-2 are detected earlier and are more sensitive than anti-S antibodies [17]. 


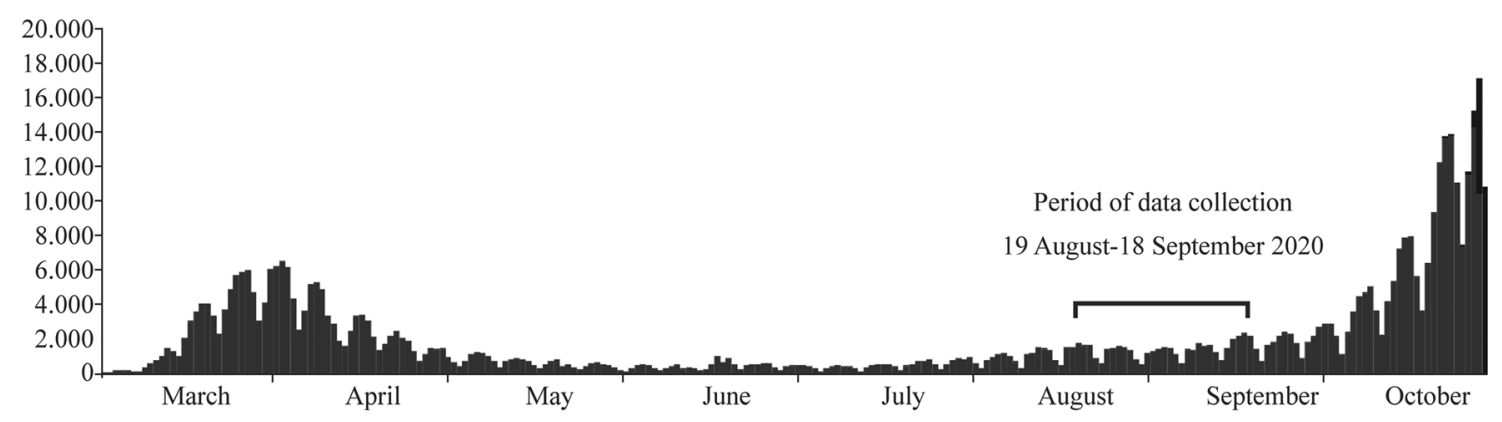

Fig. 1 New SARS-CoV-2 infections per day in Germany $(y$-axis) in the time period from March to October 2020 ( $x$-axis). Indicated is the period during which data were col-

Positive and borderline results were further tested for anti-S1 IgG antibodies using a CE-marked and FDAapproved kit "Anti-SARS-CoV-2 Elisa (IgG)" by EUROIMMUN. This assay tests for the presence of antibodies against the $\mathrm{S} 1$ structural protein, including antibodies against the receptor-binding domain of S1. Interpretation is identical to the above-mentioned anti-N ELISA. This assay has been externally validated [18-20]. The manufacturer reports a sensitivity of $80 \%$ if measured $>10$ days after symptom onset, and a specificity of $99.6 \%$. We included this second test based on the correlation between the kinetics of neutralising antibodies and those of antibodies targeting $\mathrm{S} 1$ and the receptor-binding domain $[17,21]$, to establish whether seropositive individuals were also likely to be immune to infection.

Prior to sample collection, each subject was asked to complete a short questionnaire to assess his/her individual exposure risk based on job category, time spent at work, known exposures with or without protective gear, symptoms of respiratory illness, and travel to a high-risk area. SARS-CoV-2 exposures were classified according to contact categories established by the Robert Koch Institute [22] to guide post-exposure measures [22]. "Full PPE" was specified in the questionnaire as constituting an FFP2 face mask, eye shield or goggles, gloves, and gown.

Furthermore, participants were asked how high they perceived their own risk of having previously been infected with SARS-CoV-2, as previously done by Behrens et al. at another German hospital [15]. The relevant survey question was "How high do you estimate the chance (in \%) of having been infected with the novel coronavirus already?", indicating $0 \%$ as no chance at all, and $100 \%$ as completely certain. We divided answers into groups of "very low" $(<1 \%)$, "low" (1 to $<20 \%)$, "medium" (20\% to <50\%), "high" (50\%), and "very high" (> 50\%). lected for this study. (This figure was adapted from: https:// experience.arcgis.com/experience/478220a4c454480e 823 b $17327 b 2 b f 1 d 4)$

\section{Statistical analysis}

We report absolute and relative frequencies for categorical variables, median along with interquartile range (IQR) for ordinal and continuous variables-for the whole cohort, just as by test result. Prevalence estimates of positive tests are reported along with 95\% confidence intervals (CIs) based on Clopper and Pearson [23]. Risk factors for a higher selfperceived risk were investigated with ordinal logistic regression models, results displayed as odds ratio (OR) estimates along with $95 \%$ CIs. Because only $6.7 \%$ of observations for the relevant variables were missing, a complete-case analysis was carried out. Statistical analyses were performed using $\mathrm{R}$ [24], along with additional $R$ packages for data handling and plotting [25].

\section{Results}

Between 19 August and 18 September 2020, 619 staff members were recruited, constituting $70.3 \%$ of total staff. The response rate varied among the different professions between $51.2 \%$ (service staff) and $87.3 \%$ (administrative staff).

Of the 616 participants who completed the questionnaire, $518(84.0 \%)$ were female, and the median age was 38.5 years $(\mathrm{IQR}=29.00,50.00)$. Nurses made up the majority of participants (46.0\%), followed by physicians (19.9\%), and administrative staff (8.6\%). Physicians were on average slightly younger than nurses and much older than trainees (median IQR: physicians: $38.0(32.5,45.0)$, nurses: 41.0 (30.0, 52.0), trainees: $22.0(20.0,24.3))$. The majority of participants (84.2\%) had been hired prior to the outbreak of the pandemic in Germany. Symptoms of a respiratory tract infection at any time since the beginning of the outbreak in Germany were reported by 245 participants (39.9\%), and 75 (12.2\%) had been to areas or countries considered high risk 
for SARS-CoV-2 transmission at that time by the German institute for disease control and prevention [26]. 170 participants (27.7\%) had previously been tested for SARS-CoV-2 RNA by real-time polymerase chain reaction (RT-PCR) on nasopharyngeal throat swabs in March or April 2020, out of whom $4(0.7 \%)$ had a positive result.

Previous contact with a person with a known SARS-CoV-2 infection at work was reported by 64 participants (10.4\%), and $41(64.1 \%)$ of these had occurred with full PPE, 13 without PPE and at $<2 \mathrm{~m}$ distance for more than $15 \mathrm{~min}$, and 10 without PPE and contact $>2 \mathrm{~m}$ distance. Table 1 details the characteristics of the study population by test results.

\section{Central research question}

Of the 619 screened participants, two had a positive serology for SARS-CoV-2 nucleocapsid IgG antibodies. This implies a prevalence of $0.325 \%$, with a $95 \% \mathrm{CI}$ of $0.039-1.168$. The characteristics of the two positively tested participants are displayed in detail in Table 2. All borderline test results for anti-N antibodies had negative serologies for anti-S1 antibodies.

\section{Self-perceived risk of infection}

We categorised answers into groups of "very low" $(<1 \%)$, "low" ( 1 to $<20 \%)$, "medium" ( $20 \%$ to $<50 \%)$, "high" $(50 \%)$, and "very high" ( $>50 \%)$ self-perceived risk, as illustrated in Fig. 2 by professional groups.

Self-perceived risk decreased with age, where an increase in age by 10 years reduced the odds of a higher self-perceived risk by $19 \%$ (OR, $0.81 ; 95 \%$ CI, 0.70-0.93). Having had symptoms more than doubled the odds of a high selfperceived risk (OR, 2.18; 95\% CI, 1.59-3.00). Additionally, the profession was associated with the self-perceived risk of previous infection, where compared to physicians all other professional groups had higher odds of a high self-perceived risk. The odds of higher self-perceived risk were more than two-fold for allied health staff, almost two-fold for trainees, and 1.7-fold for nurses, compared to physicians (Fig. 3). There was no significant difference in self-perceived risk between men and women, given adjustments for the other characteristics.

\section{Discussion}

After the first epidemic wave of COVID-19 in Germany, the seroprevalence of SARS-CoV-2-specific antibodies at Altona Children's Hospital was low at $0.325 \%$ (95\% CI 0.039-1.168). Self-perceived risk of a previous infection varied widely among subgroups within our sample but was consistently higher than the actual risk.

\section{Risk of COVID-19 infection in healthcare workers in general and in our study}

HCWs are a particularly high-risk group for contracting SARS-CoV-2 [11], but research has also yielded heterogeneous results. Early on during the pandemic, when adequate personal protective equipment was not routinely used, doctors exposed to COVID-19 patients had a higher seroprevalence of SARS-CoV-2-specific antibodies than their unexposed colleagues [27]. Two later studies testing HCWs by RT-PCR from nasopharyngeal swabs found infection rates similar to community incidence and found no additional exposure risk for HCWs [28, 29]. However, seroprevalences at two large hospitals in high-burden areas in Spain and Sweden were higher than the estimated average in that region [30, 31]. Yet other investigators found surprisingly low seroprevalences among HCWs, including those specifically caring for COVID-19 patients at work [12, 32] (Fig. 4).

Several factors may be responsible for this variation. PPE shortage and inconsistent use of PPE were associated with a higher SARS-CoV-2 seroprevalence in a US-American multi-centre study [39]. During the early stage of the pandemic in China, a high seroprevalence was linked to insufficient PPE use [27]. Further, there is an apparent association between community incidence and HCW seroprevalence in that community [39]. In Germany and in several other countries, the epidemic occurred in waves with defined peaks and troughs. Timing of testing in the context of these epidemic waves influences results [34] and may lead to seemingly discordant results between different studies in a similar population. Finally, sensitivities and specificities vary between different test kits and poorer quality tests may lead to relevant measurement error, particularly in small sample studies.

\section{Possible reasons for low seroprevalence measured in our study population}

Our study yielded a low seroprevalence compared to other German hospitals [15, 32], to a children's hospital in Spain [12], and to the German general public [38], although the difference to the general public was not significant. There may be several reasons for this: (1) low case load: although local SARS-CoV-2 incidence in Hamburg was consistently above the national average [40], few patients with known COVID-19 had presented to our hospital by the time we completed data collection: Out of 19,539 children and accompanying adults who presented to our hospital between 27 January and 18 September, 8,067 were tested for SARSCoV-2 by RT-PCR. Of these, only 13 were positive ( 8 inpatients or inpatients' caregivers, and 5 outpatients); (2) Universal testing: starting from 12 May 2020, every admitted patient and accompanying adult caregiver was tested for SARS-CoV-2 regardless of symptoms, further reducing the 
Table 1 Characteristics of the study population by test results

\begin{tabular}{|c|c|c|c|c|}
\hline Variables & Negative test result $(n=607)$ & Positive test result $(n=2)$ & Borderline test result $(n=7)$ & Total $(n=616)$ \\
\hline \multicolumn{5}{|l|}{ Self-perceived risk } \\
\hline Very low $(<1 \%)$ & $139(23.8 \%)$ & $0(0.0 \%)$ & $2(28.6 \%)$ & $141(23.8 \%)$ \\
\hline Low $(1$ to $<20 \%)$ & $150(25.7 \%)$ & $0(0.0 \%)$ & $2(28.6 \%)$ & $152(25.6 \%)$ \\
\hline Medium $(20$ to $<50 \%)$ & $138(23.6 \%)$ & $0(0.0 \%)$ & $1(14.3 \%)$ & $139(23.4 \%)$ \\
\hline High $(50 \%)$ & $129(22.1 \%)$ & $1(50.0 \%)$ & $1(14.3 \%)$ & $131(22.1 \%)$ \\
\hline Very high (> 50\%) & $28(4.8 \%)$ & $1(50.0 \%)$ & $1(14.3 \%)$ & $30(5.1 \%)$ \\
\hline Missing & $23(3.79 \%)$ & $0(0 \%)$ & $0(0 \%)$ & $23(3.73 \%)$ \\
\hline \multicolumn{5}{|l|}{ Age } \\
\hline Median (IQR) & $39.00(29.00,50.00)$ & $31.00(26.50,35.50)$ & $38.00(25.00,46.00)$ & $38.50(29.00,50.00)$ \\
\hline \multicolumn{5}{|l|}{ Sex } \\
\hline Female & $511(84.5 \%)$ & $2(100.0 \%)$ & $7(100.0 \%)$ & $520(84.7 \%)$ \\
\hline Male & $94(15.5 \%)$ & $0(0.0 \%)$ & $0(0.0 \%)$ & $94(15.3 \%)$ \\
\hline Missing & $2(0.33 \%)$ & $0(0 \%)$ & $0(0 \%)$ & $2(0.32 \%)$ \\
\hline \multicolumn{5}{|l|}{ Professional group } \\
\hline Physicians & $122(20.1 \%)$ & $0(0.0 \%)$ & $1(14.3 \%)$ & $123(20.0 \%)$ \\
\hline Service staff & $42(6.9 \%)$ & $0(0.0 \%)$ & $0(0.0 \%)$ & $42(6.8 \%)$ \\
\hline Trainees & $71(11.7 \%)$ & $0(0.0 \%)$ & $1(14.3 \%)$ & $72(11.7 \%)$ \\
\hline Allied health staff & $38(6.3 \%)$ & $0(0.0 \%)$ & $1(14.3 \%)$ & $39(6.3 \%)$ \\
\hline Nurses & $279(46.0 \%)$ & $2(100.0 \%)$ & $4(57.1 \%)$ & $285(46.3 \%)$ \\
\hline Administrative staff & $55(9.1 \%)$ & $0(0.0 \%)$ & $0(0.0 \%)$ & $55(8.9 \%)$ \\
\hline \multicolumn{5}{|l|}{ Date of employment } \\
\hline Before $27 / 1 / 20$ & $515(85.1 \%)$ & $1(50.0 \%)$ & $6(85.7 \%)$ & $522(85.0 \%)$ \\
\hline After $27 / 1 / 20$ & $90(14.9 \%)$ & $1(50.0 \%)$ & $1(14.3 \%)$ & $92(15.0 \%)$ \\
\hline Missing & $2(0.33 \%)$ & $0(0 \%)$ & $0(0 \%)$ & $2(0.32 \%)$ \\
\hline \multicolumn{5}{|l|}{ Part-time/full-time employment } \\
\hline$\leq 50 \%$ & $99(16.6 \%)$ & $1(50.0 \%)$ & $2(28.6 \%)$ & $102(16.9 \%)$ \\
\hline $51-75 \%$ & $128(21.5 \%)$ & $0(0.0 \%)$ & $0(0.0 \%)$ & $128(21.2 \%)$ \\
\hline $76-100 \%$ & $369(61.9 \%)$ & $1(50.0 \%)$ & $5(71.4 \%)$ & $375(62.0 \%)$ \\
\hline Missing & $11(1.81 \%)$ & $0(0 \%)$ & $0(0 \%)$ & $11(1.79 \%)$ \\
\hline \multicolumn{5}{|l|}{ Previously tested by RT-PCR } \\
\hline No previous PCR & $436(73.6 \%)$ & $1(50.0 \%)$ & $3(42.9 \%)$ & $440(73.2 \%)$ \\
\hline PCR negative & $153(25.8 \%)$ & $0(0.0 \%)$ & $4(57.1 \%)$ & $157(26.1 \%)$ \\
\hline PCR positive & $3(0.5 \%)$ & $1(50.0 \%)$ & $0(0.0 \%)$ & $4(0.7 \%)$ \\
\hline Missing & $15(2.47 \%)$ & $0(0 \%)$ & $0(0 \%)$ & $15(2.44 \%)$ \\
\hline \multicolumn{5}{|l|}{$\begin{array}{l}\text { COVID-19 contact outside of } \\
\text { work }\end{array}$} \\
\hline Yes & $18(3.0 \%)$ & $0(0.0 \%)$ & $0(0.0 \%)$ & $18(3.0 \%)$ \\
\hline Missing & $6(0.99 \%)$ & $0(0 \%)$ & $0(0 \%)$ & $6(0.97 \%)$ \\
\hline \multicolumn{5}{|l|}{ COVID-19 contact at work } \\
\hline$<2$ m away with PPE & $39(6.6 \%)$ & $0(0.0 \%)$ & $2(28.6 \%)$ & $41(6.8 \%)$ \\
\hline$<2$ m away without PPE & $13(2.2 \%)$ & $0(0.0 \%)$ & $0(0.0 \%)$ & $13(2.2 \%)$ \\
\hline$>2 \mathrm{~m}$ away without PPE & $9(1.5 \%)$ & $0(0.0 \%)$ & $1(14.3 \%)$ & $10(1.7 \%)$ \\
\hline None & $492(83.0 \%)$ & $2(100.0 \%)$ & $4(57.1 \%)$ & $498(82.7 \%)$ \\
\hline No contact with patients at all & $44(7.4 \%)$ & $0(0.0 \%)$ & $0(0.0 \%)$ & $44(7.3 \%)$ \\
\hline Missing & $14(2.31 \%)$ & $0(0 \%)$ & $0(0 \%)$ & $14(2.27 \%)$ \\
\hline \multicolumn{5}{|l|}{$\begin{array}{l}\text { Previous symptoms of respiratory } \\
\text { tract infection }\end{array}$} \\
\hline Yes & $238(39.9 \%)$ & $2(100.0 \%)$ & $4(57.1 \%)$ & $244(40.3 \%)$ \\
\hline Missing & $10(1.65 \%)$ & $0(0 \%)$ & $0(0 \%)$ & $10(1.62 \%)$ \\
\hline Travel to high risk area & & & & \\
\hline
\end{tabular}


Table 1 (continued)

\begin{tabular}{lllll}
\hline Variables & Negative test result $(n=607)$ & Positive test result $(n=2)$ & Borderline test result $(n=7)$ & Total $(n=616)$ \\
\hline Yes & $74(12.3 \%)$ & $0(0.0 \%)$ & $1(14.3 \%)$ & $75(12.3 \%)$ \\
$\quad$ Missing & $7(1.15 \%)$ & $0(0 \%)$ & $0(0 \%)$ & $7(1.14 \%)$ \\
$\begin{array}{l}\text { If travel to high risk area, country } \\
\text { visited: }\end{array}$ & & & \\
Egypt & $1(1.4 \%)$ & 0 & $0(0.0 \%)$ & $1(1.4 \%)$ \\
France & $1(1.4 \%)$ & 0 & $0(0.0 \%)$ & $1(1.4 \%)$ \\
Italy & $12(16.7 \%)$ & 0 & $0(0.0 \%)$ & $12(16.4 \%)$ \\
Austria & $45(62.5 \%)$ & 0 & $1(100.0 \%)$ & $46(63.0 \%)$ \\
Switzerland & $1(1.4 \%)$ & 0 & $0(0.0 \%)$ & $1(1.4 \%)$ \\
Spain & $9(12.5 \%)$ & 0 & $0(0.0 \%)$ & $9(12.3 \%)$ \\
USA & $3(4.2 \%)$ & 0 & $0(0.0 \%)$ & $3(4.1 \%)$
\end{tabular}

$I Q R$ interquartile range, $R T-P C R$ real-time polymerase chain reaction

Table 2 Characteristics of the two participants who tested positive for anti-N antibodies

\begin{tabular}{lll}
\hline Variables & Participant 1 & Participant 2 \\
\hline Age & 40 & 22 \\
Sex & Female & Female \\
Profession & Nurse & Nurse \\
Part-time vs full-time & Part-time ( $\leq 50 \%)$ & Full-time \\
Contact outside of work & No & No \\
Contact at work & No & No \\
Symptoms & Yes & Yes \\
Ever tested for SARS-CoV-2 by & No & Yes, positive \\
RT-PCR & & \\
Travel to high risk area & No & No \\
Self-reported risk (\%) & $50 \%$ & $100 \%$ \\
Presence of anti-S1 antibodies & No & Yes \\
\hline
\end{tabular}

$R T-P C R$ real-time polymerase chain reaction, anti-S anti-spike 1 risk of inadvertent exposure; (3) PPE use: Guidelines for adequate PPE use were instituted early on at Altona Children's Hospital, soon followed by mandatory infection prevention measures including use of a surgical mask at all times by staff, by patients above the age of 6 years, and by caregivers. As the pandemic peak in Germany occurred later than in several other countries, there was more time to prepare and to acquire resources. Overall, few SARS-CoV-2 contacts (64) were reported by study participants, and the majority of these (64.1\%) had occurred with full PPE. (4) Antibody dynamics: importantly, there may have also been a decline in antibody titres leading to a negative result in participants who had previously been infected nonetheless. This decline has been documented in follow-up studies of convalescent COVID-19 patients, particularly in asymptomatic individuals [41-43]. A study of a large community sample in England demonstrated a decline in overall seroprevalence

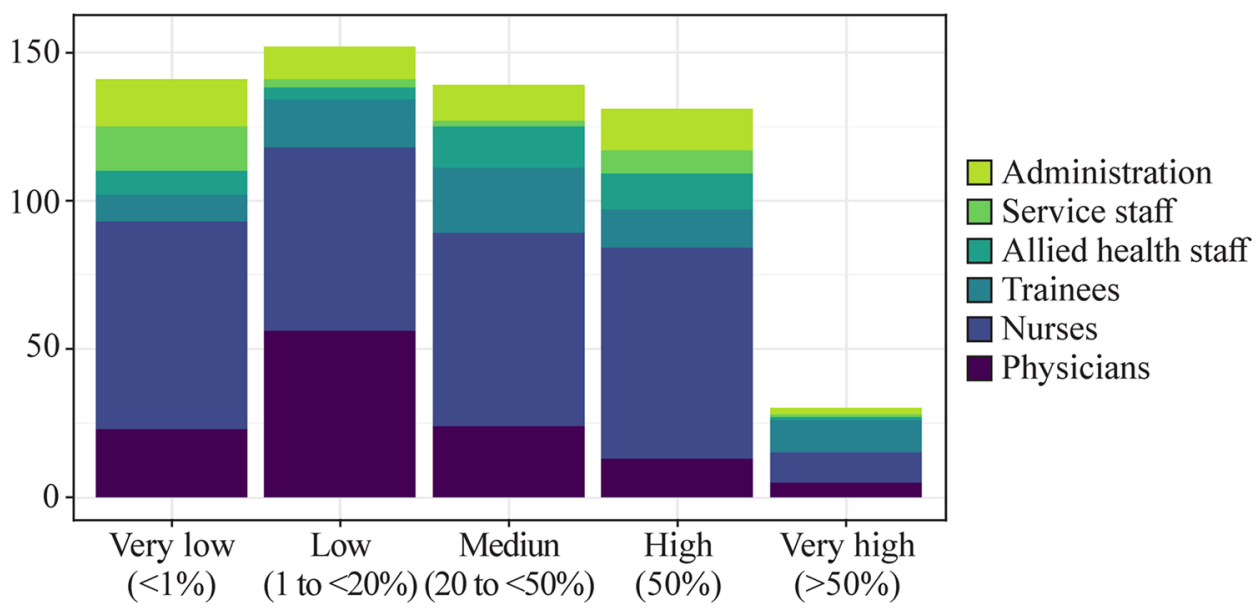

Self-perceived risk of previous SARS-CoV-2 infection

Fig. 2 Distribution of professional groups across categories of their self-perceived risk of having previously been infected with SARS-CoV-2 


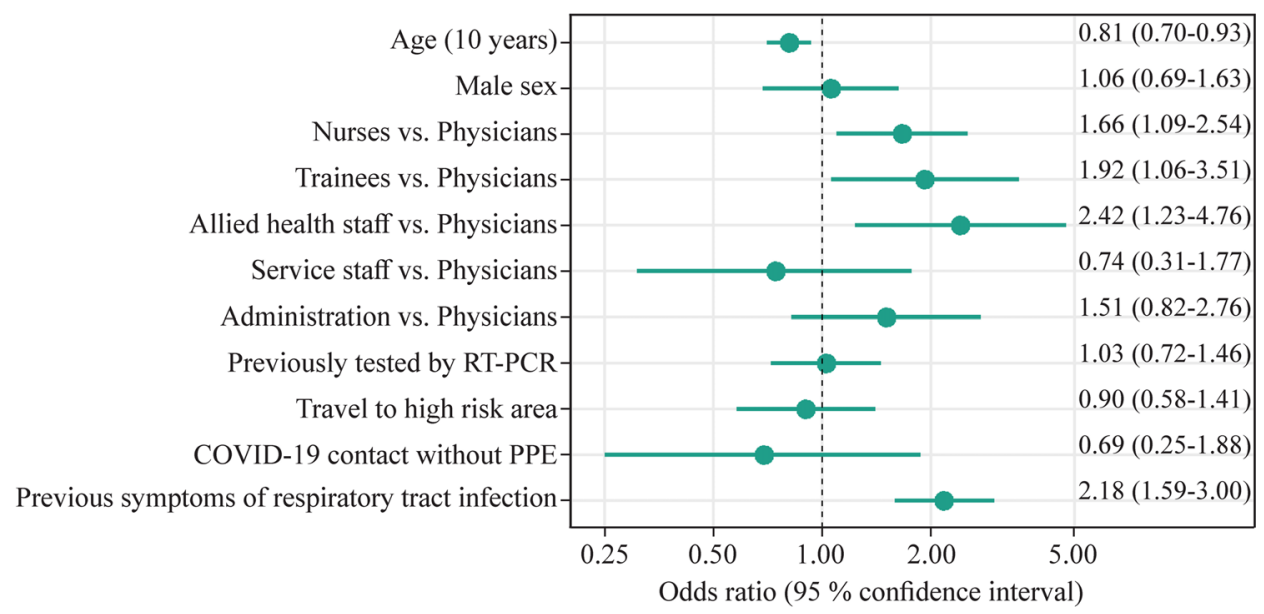

Fig. 3 Association of different characteristics with the self-perceived risk of infection. An odds ratio estimate $>1$ indicates that self-perceived risk increased when the respective characteristic was present and vice versa. The association with age is displayed in 10-year increments. Physicians were used as reference for odds ratios within professions. $R T$ - $P C R$ real-time polymerase chain reaction, $P P E$ personal protective equipment

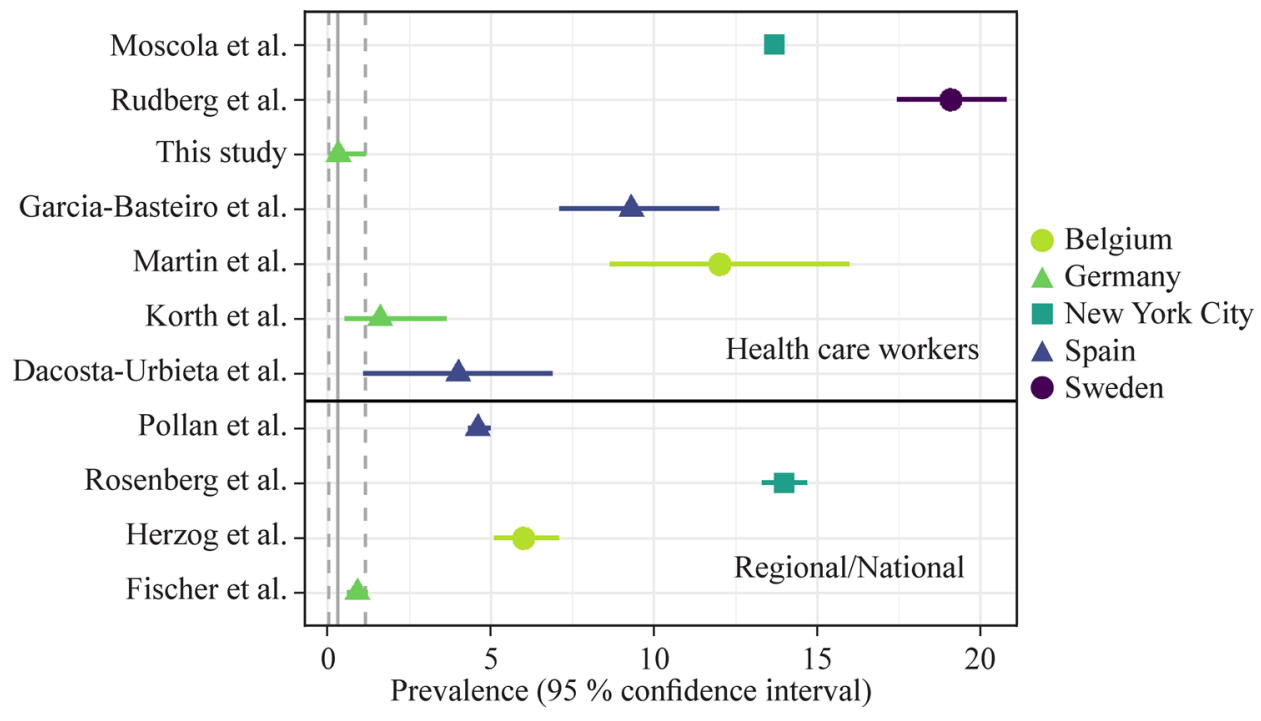

Fig. 4 Comparison of seroprevalence findings among healthcare workers with regional or national levels in various countries. This figure used data from Moscola et al. [33], Rudberg et al. [31], Garcia-Basteiro et al. [30], Martin et al. [34], Korth et al. [32], Dacosta-Urbieta et al. [12], Pollán et al.[35], Rosenberg et al.[36], Herzog et al.[37], Fischer et al.[38]

over time [44]. Also, asymptomatic patients have lower antibody titres than those recovering from severe COVID-19 [42, 43]. A previous positive RT-PCR test for SARS-CoV-2 was reported by four participants in our study, yet only one of these had measurable antibodies by the time the study was performed. All 4 had had their positive RT-PCR more than 5 months prior to serum sample collection. One had experienced no symptoms of disease. The decline in antibody titre over time, especially in asymptomatic individuals, makes seroprevalence studies for epidemiologic purposes difficult to interpret. It also poses a serious threat to any hopes for herd immunity, which is considered a key concept for epidemic control [45]. It further impacts the effectiveness of immunisations if neutralising antibody titres persist only for short periods. However, the role of T cell immunity is increasingly gaining attention. The presence of SARSCoV-2 specific memory $\mathrm{T}$ cells has been observed in seronegative convalescent individuals [46, 47], opening doors to new diagnostic strategies and guiding the development of effective vaccines [48]. 


\section{Role of children in the COVID-19 pandemic and in relation to our study findings}

An obvious question is, whether healthcare workers in pediatrics are at a lower risk for COVID-19 than their counterparts in adult medicine by virtue of a possible lower infectivity of children.

The role of children in the spread of SARS-CoV-2 remains subject to ongoing research. Dattner et al. estimate that individuals under the age of 20 years are $15 \%$ less infectious than those older than 20 years [49]. In a literature review, Goldstein et al. found children to be less susceptible to infection, but evidence confirming a lower infectivity was limited [1].

Transmission from children to other individuals does occur [50] and may [3, 51, 52] or may not [52, 53] lead to outbreaks in schools. In a German study transmission among children in schools and child care facilities was low [54]. Local COVID-19 incidence, outbreak-control strategies including social distancing at school, and early isolation of suspected cases likely play a role in whether or not an outbreak occurs [1].

Additionally, infectivity may differ between younger and older children. Fontanet et al. found that primary school children did not infect their peers, whereas high school children effectively transmitted the virus to others [52]. A South Korean team reconstructed chains of infection and found that the highest transmission among all age groups, including adults, occurred among children aged 10-19, and the lowest occurred in children aged 0-9 [55]. More than two-thirds of children presenting to our hospital are under the age of 10 years, which may be a further protective factor to our staff.

Jones et al., on the other hand, measured viral loads of SARS-CoV-2 in individuals across all age groups and found differences that were more likely due to circumstantial factors, such as timing in the course of the disease, and the authors concluded that viral loads (and, therefore, infectivity) were similar across all age groups. The lower proportion of paediatric index cases among clusters [56], therefore, may initially have been due to infections being brought in from travelling adults during the first phase of the pandemic, and not due to low infectivity of children.

Our study shows that healthcare workers who come into frequent, close contact with children and who use adequate PPE are not at a higher risk of COVID-19 exposure than the general population. However, a final conclusion about the role of children in the spread of the pandemic remains elusive.

The recent emergence of more highly transmissible SARS-CoV-2 variants, such as B.1.1.7, B.1.351, and P.1 [57-59], may alter this picture considerably.

\section{Self-perceived risk}

Perceived personal risk may be an expression of how serious the threat by the COVID-19 pandemic is considered, and of confidence placed in measures applied to limit it. It drives preventive behaviours on the one hand [13, 60, 61], but it also predicts negative mental health outcomes [60, 62]. A nationwide survey in Germany found that $60 \%$ of HCWs had concerns regarding their own health [14]. Behrens et al. found that perceived risk among HCWs at a German hospital was considerable while actual seroprevalence was low [15].

Of note, we had asked participants about perceived probability of having already been infected in the past, whereas many other studies ask about perceived risk of a future infection [13, 60, 62]. The positive correlation with previous symptoms of a respiratory illness is, therefore, unsurprising. The negative association with age and the variability among different professions are more difficult to interpret. We controlled for confounding by the measured variables, but we cannot exclude confounding by other factors.

While self-perceived risk in the form of a probability score cannot be directly compared to seroprevalence, we find a definite discrepancy between the two. More than a quarter $(n=131)$ of study participants rated their risk at $50 \%$ or higher, whereas only $0.325 \%(n=2)$ had a positive antibody test. This probably reflects the uncertainty within a pandemic with a pathogen not well understood at the time, where the general narrative is that healthcare workers are at a particularly high risk of infection. In a cohort that was informed of its serological test results, which were mostly negative, self-perceived risk decreased significantly [15].

Understanding risk perceptions in the general public and among subgroups may ultimately guide effective communication about the pandemic to the public.

\section{Strengths and limitations}

Participation was largely based on voluntary response to generalised announcements and some targeted requests. The overall response was high $(70.3 \%)$, but response from trainees and service staff was below the overall response rate, and administrative staff, physicians, and allied health staff were represented to a greater extent. However, this is the only hint for non-representative sampling. Almost all children presenting to our hospital are accompanied by an adult; therefore, staff is exposed to both populations almost equally and the measured seroprevalence must be interpreted in this context. As mentioned, antibody titres may decline over time, compromising the epidemiological value of our results. Risk perception could have been related to individual understanding of COVID-19. 
In conclusion, SARS-CoV-2 seroprevalence is low among healthcare workers at a large children's hospital in Germany after the first epidemic wave. Several protective factors may play a role, including low local COVID-19 incidence, use of personal protective equipment, and screening of inpatients. The seroprevalence is far from a level that confers herd immunity. Because the second epidemic wave strikes with greater force than the first, it is important to remember that the above-mentioned preventive measures work and should be continued. The discrepancy between perceived risk of infection and actual seroprevalence may be a reflection of the general narrative that healthcare workers are at a particularly high risk of infection.

Author contributions $\mathrm{MN}$ and AA contributed equally to this paper as co-first authors. MN: conceptualisation, investigation, data curation, project administration, writing —original draft; AA: formal analysis, methodology, data curation, visualisation, writing-original draft, writing-review and editing; ER: investigation, project administration; DS: investigation, project administration; MM: investigation, project administration; JS: conceptualisation, investigation, methodology, resources; RS: conceptualisation, supervision; IK: conceptualisation, investigation, project administration, supervision, writing - review and editing; PS: conceptualisation, funding acquisition, project administration, supervision. IK and PS contributed equally as the last authors.

Funding Open Access funding enabled and organized by Projekt DEAL. This study was supported by Altona Children's Hospital $\mathrm{GmbH}$. Altona Children's Hospital GmbH. No external funding was received.

Data availability All data will be made available upon request.

\section{Compliance with ethical standards}

Ethical approval This study was approved by the Ethical Review Committee of the Medical Association (Aerztekammer) Hamburg in Germany (PV7404). Informed consent to participate in the study was obtained from participants.

Conflict of interest No financial or non-financial benefits have been received or will be received from any party related directly or indirectly to the subject of this article. The authors declare no financial or non-financial conflicts of interest related to this study.

Consent to participate Written informed consent was obtained from all participants prior to participation in the study.

Open Access This article is licensed under a Creative Commons Attribution 4.0 International License, which permits use, sharing, adaptation, distribution and reproduction in any medium or format, as long as you give appropriate credit to the original author(s) and the source, provide a link to the Creative Commons licence, and indicate if changes were made. The images or other third party material in this article are included in the article's Creative Commons licence, unless indicated otherwise in a credit line to the material. If material is not included in the article's Creative Commons licence and your intended use is not permitted by statutory regulation or exceeds the permitted use, you will need to obtain permission directly from the copyright holder. To view a copy of this licence, visit http://creativecommons.org/licenses/by/4.0/.

\section{References}

1. Goldstein E, Lipsitch M, Cevik M. On the effect of age on the transmission of SARS-CoV-2 in households, schools, and the community. J Infect Dis. 2021;223:362-9.

2. Nassih H, El Fakiri K, Sab IA. Absence of evidence of transmission of Coronavirus Disease 2019 from a young child to mother despite prolonged contact. Indian J Pediatr. 2020;87:754.

3. Otte im Kampe E, Lehfeld A, Buda S, Buchholz U, Haas W. Surveillance of COVID-19 school outbreaks, Germany, March to August 2020. Euro Surveill. 2020;25:2001645. https://doi.org/ 10.2807/1560-7917.ES.2020.25.38.2001645.

4. Dong QQ, Qiu LR, Cheng LM, Shu SN, Chen Y, Zhao Y, et al. Kindergartens reopening in the period of regular epidemic prevention and control, benefitial or harmful? Curr Med Sci. 2020;40:817-21.

5. Lu X, Zhang L, Du H, Zhang J, Li YY, Qu J, et al. SARS-CoV-2 infection in children. N Engl J Med. 2020;382:1663-5.

6. Park JY, Han MS, Park KU, Kim JY, Choi EH. First pediatric case of coronavirus disease 2019 in Korea. J Korean Med Sci. 2020;35:

7. Lee PI, Hu YL, Chen PY, Huang YC, Hsueh PR. Are children less susceptible to COVID-19? J Microbiol Immunol Infect. 2020;53:371-2.

8. Li Y, Guo F, Cao Y, Li L, Guo Y. Insight into COVID-2019 for pediatricians. Pediatr Pulmonol. 2020;55:E1-4.

9. Hippich M, Holthaus L, Assfalg R, Zapardiel-Gonzalo J, Kapfelsperger $\mathrm{H}$, Heigermoser $\mathrm{M}$, et al. A public health antibody screening indicates a 6-fold higher SARS-CoV-2 exposure rate than reported cases in children. Med (N Y). 2021;2:149.e4-63.e4.

10. Lietz J, Westermann C, Nienhaus A, Schablon A. The occupational risk of Influenza A (H1N1) infection among Healthcare Personnel during the 2009 pandemic: a systematic review and metaanalysis of observational studies. PLoS One. 2016;11:e0162061.

11. Sahu AK, Amrithanand VT, Mathew R, Aggarwal P, Nayer J, Bhoi S. COVID-19 in health care workers-a systematic review and meta-analysis. Am J Emerg Med. 2020;38:1727-31.

12. Dacosta-Urbieta A, Rivero-Calle I, Pardo-Seco J, RedondoCollazo L, Salas A, Gómez-Rial J, et al. Seroprevalence of SARSCoV-2 among pediatric healthcare workers in Spain. Front Pediatr. 2020;8:547.

13. Wise T, Zbozinek TD, Michelini G, Hagan CC, Mobbs D. Changes in risk perception and self-reported protective behaviour during the first week of the COVID-19 pandemic in the United States. R Soc Open Sci. 2020;7:200742.

14. Paffenholz P, Peine A, Hellmich M, Paffenholz SV, Martin L, Luedde M, et al. Perception of the 2020 SARS-CoV-2 pandemic among medical professionals in Germany: results from a nationwide online survey. Emerg Microbes Infect. 2020;9:1590-9.

15. Behrens GMN, Cossmann A, Stankov MV, Schulte B, Streeck H, Förster R, et al. Strategic anti-SARS-CoV-2 serology testing in a low prevalence setting: the COVID-19 contact (CoCo) study in healthcare professionals. Infect Dis Therapy. 2020;9:837-49.

16. Leung DT, Tam FC, Ma CH, Chan PK, Cheung JL, Niu H, et al. Antibody response of patients with severe acute respiratory syndrome (SARS) targets the viral nucleocapsid. J Infect Dis. 2004;190:379-86.

17. Brochot E, Demey B, Touzé A, Belouzard S, Dubuisson J, Schmit JL, et al. Anti-spike, anti-nucleocapsid and neutralizing antibodies in SARS-CoV-2 inpatients and asymptomatic individuals. Front Microbiol. 2020;11:584251. 
18. Schnurra C, Reiners N, Biemann R, Kaiser T, Trawinski H, Jassoy C. Comparison of the diagnostic sensitivity of SARS-CoV-2 nucleoprotein and glycoprotein-based antibody tests. J Clin Virol. 2020;129:104544.

19. Meyer B, Torriani G, Yerly S, Mazza L, Calame A, Arm-Vernez I, et al. Validation of a commercially available SARS-CoV-2 serological immunoassay. Clin Microbiol Infect. 2020;26:1386-94.

20. Jääskeläinen AJ, Kekäläinen E, Kallio-Kokko H, Mannonen L, Kortela E, Vapalahti O, et al. Evaluation of commercial and automated SARS-CoV-2 IgG and IgA ELISAs using coronavirus disease (COVID-19) patient samples. Euro Surveill. 2020;25:2000603.

21. Wu F, Wang A, Liu M, Wang Q, Chen J, Xia S, et al. Neutralizing antibody responses to SARS-CoV-2 in a COVID-19 recovered patient cohort and their implications. medRxiv. 2020. https://doi. org/10.1101/2020.03.30.20047365.

22. Robert Koch Institute. SARS-CoV-2 contact tracing. 2020. https:// www.rki.de/DE/Content/InfAZ/N/Neuartiges_Coronavirus/Konta ktperson/Management.html. Accessed 20 May 2020.

23. Clopper CJ, Pearson ES. The use of confidence or fiducial limits illustrated in the case of the binomial. Biometrika. 1934;26:404-13.

24. R Core Team. R: A language and environment for statistical computing. Vienna: R Foundation for Statistical Computing; 2018.

25. Wickham H, Averick M, Bryan J, Chang W, McGowan L, François R. Welcome to Tidyverse. J Open Source Softw. 2019;4:1686.

26. Robert Koch Institute. Information on the designation of international risk areas by the Federal Foreign Office, the Federal Ministry of Health, and the Federal Ministry of the Interior, Building and Community. 2020. https://www.rki.de/DE/Content/InfAZ/N/ Neuartiges_Coronavirus/Risikogebiete_neu.html. Accessed 12 Apr 2020.

27. Chen Y, Tong X, Wang J, Huang W, Yin S, Huang R, et al. High SARS-CoV-2 antibody prevalence among healthcare workers exposed to COVID-19 patients. J Infect. 2020;81:420-6.

28. Kluytmans-van den Bergh MFQ, Buiting AGM, Pas SD, Bentvelsen RG, van den Bijllaardt W, van Oudheusden AJG, et al. Prevalence and clinical presentation of health care workers with symptoms of coronavirus disease, et al. in 2 Dutch hospitals during an early phase of the pandemic. JAMA Netw Open. 2019;2020:e209673.

29. Folgueira MD, Muñoz-Ruipérez C, Alonso-López MÁ, Delgado R. SARS-CoV-2 infection in health care workers in a large public hospital in Madrid, Spain, during March 2020. medRxiv. 2020. https://doi.org/10.1101/2020.04.07.20055723.

30. Garcia-Basteiro AL, Moncunill G, Tortajada M, Vidal M, Guinovart C, Jiménez A, et al. Seroprevalence of antibodies against SARS-CoV-2 among health care workers in a large Spanish reference hospital. Nat Commun. 2020;11:3500.

31. Rudberg AS, Havervall S, Månberg A, Jernbom Falk A, Aguilera $\mathrm{K}, \mathrm{Ng} \mathrm{H}$, et al. SARS-CoV-2 exposure, symptoms and seroprevalence in healthcare workers in Sweden. Nat Commun. 2020;11:5064.

32. Korth J, Wilde B, Dolff S, Anastasiou OE, Krawczyk A, Jahn $\mathrm{M}$, et al. SARS-CoV-2-specific antibody detection in healthcare workers in Germany with direct contact to COVID-19 patients. J Clin Virol. 2020;128:104437

33. Moscola J, Sembajwe G, Jarrett M, Farber B, Chang T, McGinn T, et al. Prevalence of SARS-CoV-2 antibodies in health care personnel in the New York City Area. JAMA. 2020;324:893-5.

34. Martin C, Montesinos I, Dauby N, Gilles C, Dahma H, Van Den Wijngaert $S$, et al. Dynamics of SARS-CoV-2 RT-PCR positivity and seroprevalence among high-risk healthcare workers and hospital staff. J Hosp Infect. 2020;106:102-6.

35. Pollán M, Pérez-Gómez B, Pastor-Barriuso R, Oteo J, Hernán MA, Pérez-Olmeda M, et al. Prevalence of SARS-CoV-2 in Spain
(ENE-COVID): a nationwide, population-based seroepidemiological study. Lancet. 2020;396:535-44.

36. Rosenberg ES, Tesoriero JM, Rosenthal EM, Chung R, Barranco MA, Styer LM, et al. Cumulative incidence and diagnosis of SARS-CoV-2 infection in New York. Ann Epidemiol. 2020;48:23. e4-9.e4.

37. Herzog S, De Bie J, Abrams S, Wouters I, Ekinci E, Patteet L, et al. Seroprevalence of $\operatorname{IgG}$ antibodies against SARS coronavirus 2 in Belgium - a serial prospective cross-sectional nationwide study of residual samples. medRxiv. 2020. https://doi.org/ 10.1101/2020.06.08.20125179.

38. Fischer B, Knabbe C, Vollmer T. SARS-CoV-2 IgG seroprevalence in blood donors located in three different federal states, Germany, March to June 2020. Euro Surveill. 2020;25:2001285.

39. Self WH, Tenforde MW, Stubblefield WB, Feldstein LR, Steingrub JS, Shapiro NI, et al. Seroprevalence of SARS-CoV-2 among frontline health care personnel in a multistate hospital network-13 Academic Medical Centers, April-June 2020. MMWR Morb Mortal Wkly Rep. 2020;69:1221-6.

40. Robert Koch Institut. Aktueller Lage-/Situationsbericht des RKI zu COVID-19, 24/11/2020. 2020. https://www.rki.de/DE/Conte nt/InfAZ/N/Neuartiges_Coronavirus/Situationsberichte/Gesamt. html. Accessed 25 Nov 112020.

41. Ibarrondo FJ, Fulcher JA, Goodman-Meza D, Elliott J, Hofmann C, Hausner MA, et al. Rapid decay of anti-SARS-CoV-2 antibodies in persons with mild Covid-19. N Engl J Med. 2020;383:1085-7.

42. Bruni M, Cecatiello V, Diaz-Basabe A, Lattanzi G, Mileti E, Monzani S, et al. Persistence of anti-SARS-CoV-2 antibodies in non-hospitalized COVID-19 convalescent health care workers. J Clin Med. 2020;9:3188. https://doi.org/10.3390/jcm9103188.

43. Long QX, Tang XJ, Shi QL, Li Q, Deng HJ, Yuan J, et al. Clinical and immunological assessment of asymptomatic SARS-CoV-2 infections. Nat Med. 2020;26:1200-4.

44. Ward H, Cooke G, Atchison C, Whitaker M, Elliott J, Moshe M, et al. Declining prevalence of antibody positivity to SARS-CoV-2: a community study of 365,000 adults. medRxiv. 2020. https://doi. org/10.1101/2020.10.26.20219725.

45. Fontanet A, Cauchemez S. COVID-19 herd immunity: where are we? Nat Rev Immunol. 2020;20:583-4.

46. Sekine T, Perez-Potti A, Rivera-Ballesteros O, Strålin K, Gorin JB, Olsson A, et al. Robust T cell immunity in convalescent individuals with asymptomatic or Mild COVID-19. Cell. 2020;183:158. e14-68.e14.

47. Gallais F, Velay A, Nazon C, Wendling M, Partisani M, Sibilia $\mathrm{J}$, et al. Intrafamilial Exposure to SARS-CoV-2 associated with cellular immune response without seroconversion. France. Emerg Infect Dis. 2021;27:113-21. https://doi.org/10.3201/eid2701. 203611.

48. Altmann DM, Boyton RJ. SARS-CoV-2 T cell immunity: specificity, function, durability, and role in protection. Sci Immunol. 2020;5: eabd6160.

49. Dattner I, Goldberg Y, Katriel G, Yaari R, Gal N, Miron Y, et al. The role of children in the spread of COVID-19: Using household data from Bnei Brak, Israel, to estimate the relative susceptibility and infectivity of children. PLoS Comput Biol. 2021;17:e1008559.

50. Lopez AS, Hill M, Antezano J, Vilven D, Rutner T, Bogdanow L, et al. Transmission dynamics of COVID-19 outbreaks associated with child care facilities-Salt Lake City, Utah, April-July 2020. MMWR Morb Mortal Wkly Rep. 2020;69:1319-23.

51. Stein-Zamir C, Abramson N, Shoob H, Libal E, Bitan M, Cardash T, et al. A large COVID-19 outbreak in a high school 10 days after schools' reopening, Israel, May 2020. Euro Surveill. 2020;25:2001352. https://doi.org/10.2807/1560-7917.ES.2020. 25.29.2001352. 
52. Fontanet A, Tondeur L, Grant R, Temmam S, Madec Y, Bigot T, et al. SARS-CoV-2 infection in schools in a northern French city: a retrospective serological cohort study in an area of high transmission, France, January to April 2020. Euro Surveill. 2021;26:2001695. https://doi.org/10.2807/1560-7917.ES.2021.26.15.2001695.

53. Heavey L, Casey G, Kelly C, Kelly D, McDarby G. No evidence of secondary transmission of COVID-19 from children attending school in Ireland, 2020. Eurosurveillance. 2020;25:2000903.

54. Ehrhardt J, Ekinci A, Krehl H, Meincke M, Finci I, Klein J, et al. Transmission of SARS-CoV-2 in children aged 0 to 19 years in childcare facilities and schools after their reopening in May 2020, Baden-Württemberg, Germany. Euro Surveill. 2020;25:2001587. https://doi.org/10.2807/1560-7917.ES.2020.25.36.2001587.

55. Park YJ, Choe YJ, Park O, Park SY, Kim YM, Kim J, et al. Contact tracing during coronavirus disease outbreak, South Korea, 2020. Emerg Infect Dis. 2020;26:2465-8.

56. Zhu Y, Bloxham CJ, Hulme KD, Sinclair JE, Tong ZWM, Steele LE, et al. A meta-analysis on the role of children in severe acute respiratory syndrome coronavirus 2 in household transmission clusters. Clin Infect Dis. 2020;72:e1146-53.

57. Volz E, Mishra S, Chand M, Barrett JC, Johnson R, Geidelberg L, et al. Transmission of SARS-CoV-2 Lineage B.1.1.7 in England: Insights from linking epidemiological and genetic data. medRxiv. 2021. https://doi.org/10.1101/2020.12.30.20249034.
58. Tegally H, Wilkinson E, Giovanetti M, Iranzadeh A, Fonseca V, Giandhari J, et al. Emergence and rapid spread of a new severe acute respiratory syndrome-related coronavirus 2 (SARS-CoV-2) lineage with multiple spike mutations in South Africa. medRxiv. 2020. https://doi.org/10.1101/2020.12.21. 20248640.

59. Faria NR, Mellan TA, Whittaker C, Claro IM, Candido DDS, Mishra S, et al. Genomics and epidemiology of the P.1 SARSCoV-2 lineage in Manaus, Brazil. Science. 2021;372:815-21. https://doi.org/10.1126/science.abh2644.

60. Harper CA, Satchell LP, Fido D, Latzman RD. Functional fear predicts public health compliance in the COVID-19 pandemic. Int J Ment Health Addict. 2020. https://doi.org/10.1007/ s11469-020-00281-5.

61. Bish A, Michie S. Demographic and attitudinal determinants of protective behaviours during a pandemic: a review. Br J Health Psychol. 2010;15:797-824.

62. Kim AW, Nyengerai T, Mendenhall E. Evaluating the mental health impacts of the COVID-19 pandemic: perceived risk of COVID-19 infection and childhood trauma predict adult depressive symptoms in urban South Africa. Psychol Med. 2020;1-13.

Publisher's Note Springer Nature remains neutral with regard to jurisdictional claims in published maps and institutional affiliations. 